\title{
Extravasation of fluid in arthroscopic shoulder surgery requiring prolonged intubation: a case report
}

\author{
Brandon R. Vier ${ }^{1}$, Kyle W. Mombell ${ }^{1}$, Erin L. Gagliano ${ }^{2}$, Nicole M. King ${ }^{2}$ and Lucas S. McDonald ${ }^{1 *}$ (D)
}

\begin{abstract}
Background: Shoulder arthroscopy is a safe and effective procedure with a low complication rate. Although rare, there are potentially life-threatening risks such as fluid extravasation causing airway compromise.

Case presentation: We report the case of a 65-year-old female treated with an arthroscopic rotator cuff repair who had significant extravasation of arthroscopic fluid causing severe facial and neck swelling. Overnight intubation was required for respiratory monitoring until the edema had resolved enough to allow safe extubation.

Conclusion: This case highlights the risk factors and clinical course of a patient with airway compromise caused by extravasation of fluid during shoulder arthroscopy. Although shoulder arthroscopy is a safe procedure, surgeon familiarity with the risk factors for this complication and close monitoring can aid in its identification and allow for appropriate treatment.
\end{abstract}

Keywords: Shoulder, Arthroscopy, Fluid extravasation, Airway

\section{Background}

Shoulder arthroscopy facilitates a minimally invasive approach to the joint compared to open procedures which are inherently more traumatic to the soft tissues. Arthroscopy has its own unique complications primarily related to the need for distension of the operative joint with pressurized irrigation fluid to aid in visualization. Extravasation of irrigation fluid and even air into the surrounding soft tissues has previously been with the most significant consequence of this extravasation is edema resulting in airway compromise [1].

Most of the earlier published cases involved patients undergoing arthroscopy under regional anesthesia where the patients vocalized symptoms of impending airway compromise [2-6], but more recent literature describes cases with general anesthesia where the edema isn't recognized until just prior to or even after extubation/removal of an laryngeal mask airway (LMA) [7-9]. Edema can be quite profound and extend into the chest, neck, and even into the face making the tissue tense and cool

\footnotetext{
* Correspondence: Lucas.S.McDonald.mil@mail.mil

${ }^{1}$ Department of Orthopedic Surgery, Naval Medical Center San Diego, 34800

Bob Wilson Dr, San Diego, CA, USA

Full list of author information is available at the end of the article
}

to palpation. In the majority of cases, the patient remains intubated, or if needed, is urgently intubated for airway protection and monitored for 24 to $48 \mathrm{~h}$ until the edema has sufficiently resolved to permit safe extubation.

While the glenohumeral joint has a capsule that may provide an anatomic barrier to fluid extravasation, it is has been postulated that the lack of such a capsule in the subacromial space allows for fluid extravasation during arthroscopy $[10,11]$. Anatomical variants also exist including aberrant connections between the glenohumeral joint and soft tissues of the neck via the infraspinatous fossa [7]. Additionally, rotator cuff tears and iatrogenic anterior deltoid tears are potential risk factors for fluid extravasation [4].

A multitude of other risk factors are identified in the literature. Obese patients have multiple tissue planes that may allow fluid to spread more easily into the surrounding soft tissue [4]. Patient positioning in the lateral decubitus position increases the risk of significant edema in the neck due to its dependent position during the procedure [2]. High pump pressures and prolonged surgical times have are additional risk factors for fluid extravasation $[2,6,8,10]$. Deltoid pressure monitoring 


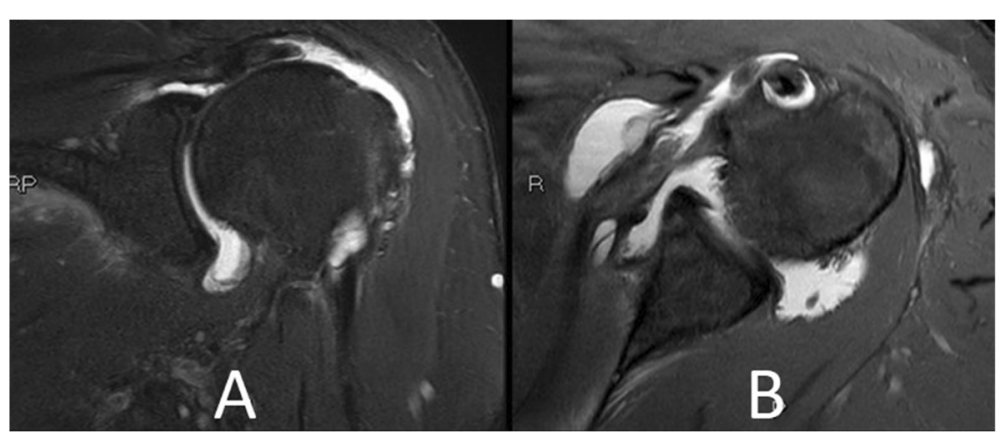

Fig. 1 Magnetic Resonance Imaging (MRI) images depicting the retracted full-thickness tear of the supraspinatus tendon (a) and partial-thickness tear of the upper border of the subscapularis tendon (b)

during arthroscopy demonstrated that the intramuscular pressure significantly increases during arthroscopic acromioplasty, routinely reaching $50-120 \mathrm{mmHg}$, and that adduction and external rotation of the shoulder cause these pressures to elevate up to $150 \mathrm{mmHg}^{10}$.

We describe a case where arthroscopic rotator cuff repair in a patient with several risk factors for fluid extravasation resulted in facial and neck edema requiring prolonged intubation and respiratory monitoring overnight.

The patient provided written consent for publication.

\section{Case presentation}

A 65-year-old female with a body mass index of 29 presented with a 7-month history of left shoulder pain and weakness. Physical exam and diagnostic imaging were consistent with a symptomatic full thickness rotator cuff tear of the supraspinatus and a partial tear of the subscapularis tendon (Fig. 1). She was indicated for an elective arthroscopic surgical repair. She was otherwise healthy with her only medical comorbidity consisting of hyperlipidemia. She had no prior surgical history including no prior shoulder procedures.

Anesthesia evaluation on the day of surgery was performed and her neck was recorded as "unremarkable."
She was assigned an American Society of Anesthesiologists (ASA) score of 2. On the day of surgery, she was easily intubated with an endotracheal tube in the supine position and then placed in the standard lateral decubitus position for arthroscopic shoulder surgery. Exam under anesthesia was performed followed by a diagnostic shoulder arthroscopy. Normal saline was fed into a Stryker CrossFlow ${ }^{\circ}$ Integrated Arthroscopy Pump (Stryker Endoscopy, San Jose, CA, USA) set at $25 \mathrm{mmHg}$ initially. Epinephrine was not added to the irrigation fluid. Shortly after beginning the case, the arthroscopic fluid pressure was raised to $35 \mathrm{mmHg}$ to aid in visualization where it remained for the duration of the case. No lavage cycles were utilized. Standard posterior, anterosuperior and anteroinferior portals were placed as well as a lateral working portal. She was found to have a type 1 superior labrum anterior to posterior (SLAP) tear, degenerative changes in the anterior, inferior and posterior labrum, a subscapularis tear in the upper one third which was retracted medially, and a complete supraspinatus tear. A biceps tenotomy was performed followed by rotator cuff repair of the subscapularis and supraspinatus tears utilizing suture anchors. Bone quality was remarkably poor with pull-out of multiple suture anchors during the rotator cuff repair

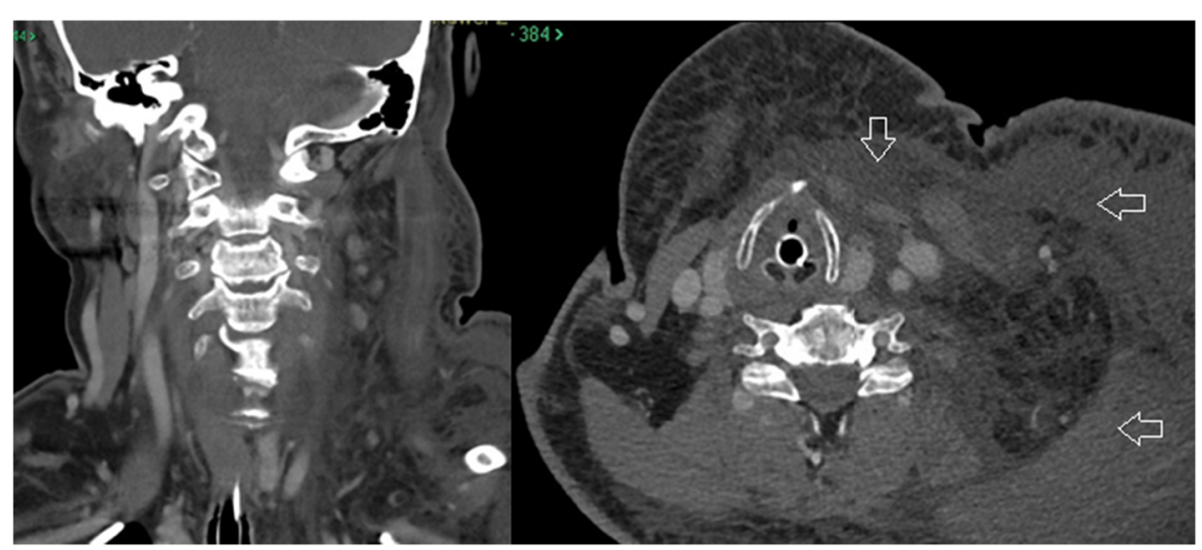

Fig. 2 CT scan showing paratracheal edema 
adding to surgical complexity and time. Total operative time was $3 \mathrm{~h}$ and $53 \mathrm{~min}$. Upon completion of the case and removal of the surgical drapes, significant unilateral face and neck swelling was noted on the side of the operative shoulder (the non-gravity dependent side). Upon consultation with the anesthesia providers the decision was made to obtain a computed tomography (CT) scan for visualization of the soft tissues surrounding the airway, with a plan to leave the patient intubated overnight. The CT demonstrated diffuse soft tissue edema in the subcutaneous tissues of the neck, chest and face. The airway was deviated at the level of the trachea due to the paratracheal edema. There was no focal collection or extravasated contrast indicative of a hematoma or vascular injury (Fig. 2).

The patient was monitored overnight in the Intensive Care Unit (ICU). After resolution of the edema, she met standard ICU extubation criteria, and was extubated on the morning of postoperative day one. Postoperatively, the patient has done well without any airway or pulmonary complications, complete resolution of preoperative symptoms, and return to baseline shoulder function (Fig. 3).

\section{Discussion}

In this case, the patient was intubated for the duration of the procedure, which ensured airway protection and obviated the need for intubation upon recognition of the condition. Had the procedure been performed under regional anesthesia with sedation or with a laryngeal mask airway (LMA) a conversion to an endotracheal airway would have been required. Fortunately, inspection of the neck and surrounding soft tissues prior to extubation identified this complication and the patient remained intubated in a monitored setting until extubation was safe.
A CT of the neck and chest was requested by the anesthesia team to assess for laryngeal edema. Additional strategies exist to assess for a potentially compromised airway. If the edema is noted before extubation of the patient, a cuff-leak test can be performed. This involves deflating the cuff of the endotracheal tube and then digitally occluding it. If the patient is able to breath around the deflated cuff, it is hypothesized they are at lower risk for post-extubation stridor and need for reintubation. Results of this test have varied widely depending on patient population and study so results of the test should be utilized in conjunction with other clinical tools [12, 13]. Furthermore, if the edema is noted during the case, the patient can be repositioned to the beach chair position to allow gravity to pull the fluid away from the airway, or the case can be converted to an open procedure.

Established risk factors for fluid extravasation present in this case included lateral decubitus positioning, prolonged operative time, and performing a subacromial decompression. These represent modifiable risk factors and are important preoperative and intraoperative considerations for the treating surgeon. Adequate visualization of the surgical field during shoulder arthroscopy is a necessity, but the surgeon should have an understanding of the risks of elevated pump pressures and liberal use of lavage cycles. Visualization of the subacromial space can be aided by narrowing the pressure differential between the arthroscopic pressure in this space and the systolic blood pressure. Morrison et al. demonstrated that the visual clarity of the subacromial space in the lateral decubitus position was excellent as long as there was a pressure difference of less than 49 $\mathrm{mmHg}$. This pressure differential can be maintained through a combination relative hypotensive anesthesia

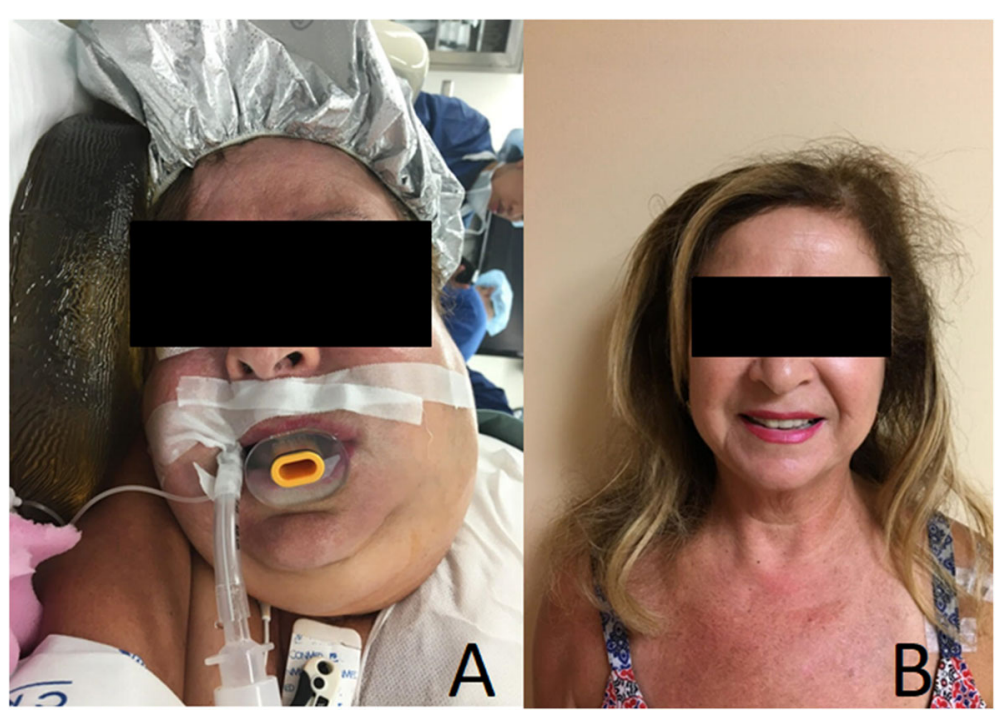

Fig. 3 Clinical photo showing intraoperative facial edema (a) and complete resolution at two week follow up (b) 
and higher pump pressures [14, 15]. The surgeon and anesthesia provider must make a conscious effort to balance these two variables in order to maintain the visualization necessary for surgery but avoid complications from excessive hypotension or extreme pump pressures.

Although the risk of fluid extravasation may be decreased with the beach chair position, this positioning is also not without risk. Beach chair positioning carries a higher risk of cerebral hypoperfusion especially with relative hypotensive anesthesia. It also carries higher rates of venous and arterial air embolism, and even quadriplegia from incorrect head positioning during surgery $[14,15]$.

Memon et al. conducted a systematic review of the published literature concerning fluid extravasation as result of shoulder arthroscopy. Approximately $65 \%$ of the patients who experienced fluid extravasation were positioned in the lateral decubitus position compared to $30 \%$ in the beach chair position. The authors also suggest limiting the pump pressures to less than $150 \mathrm{mmHg}$. Utilizing a gravity feed irrigation setup may be a safer alternative to pump systems which result in higher intraarticular pressures [16-18]. Their literature review also found that symptomatic patients had irrigation volumes of between 20 and $36 \mathrm{~L}$ and suggest limiting the total irrigation volume to $20 \mathrm{~L}$. [16]

Total operative time is directly proportional to the volume of irrigation fluid used and subsequent weight gain by the patient, presumably from absorption of the irrigation fluid [19]. Although there is no clear safe upper limit for operative times, some authors suggest limiting surgical time to between 90 and $120 \mathrm{~min}$ to reduce this risk $[16,20]$.

Fluid extravasation not only affects the local soft tissues but may have other systemic complications such as electrolyte disturbances. Ichai et al. demonstrated that there is systemic absorption of glycine irrigation fluid during shoulder arthroscsopy. Although the absorption of glycine may be different than that of other irrigation fluids including normal saline or Ringer's lactate, the authors suggest that the risk of significant systemic absorption can be mitigated with lower pump pressures and a lower volume of irrigation fluid used during arthroscopy $[16,21]$.

\section{Conclusions}

Shoulder arthroscopy is a generally safe and effective procedure, but surgeons and anesthesia providers must be aware of the rare and potentially life-threatening complication of fluid extravasation and airway compromise. Risk factors such as lateral decubitus positioning, obesity, high pump pressures, and long operative times may increase this risk. Surgeons and anesthesia providers should consider routine endotracheal intubation in arthroscopic shoulder procedures with multiple risk factors for dangerous fluid extravasation.

\section{Abbreviations}

ASA: American Society of Anesthesiologists; CT: Computed Tomography; ICU: Intensive Care Unit; LMA: Laryngeal Mask Airway; MRI: Magnetic Resonance Imaging; SLAP: Superior Labrum Anterior to Posterior

\section{Acknowledgements}

Not applicable.

The views expressed herein are those of the authors and do not necessarily reflect the official policy or position of the Department of the Navy,

Department of Defense, nor the U.S. Government.

\section{Authors' contributions}

BV was a major contributor in performing a literature search and writing the manuscript. KM aided in literature search and editing the manuscript. EG contributed to editing the manuscript. NK contributed to editing the manuscript. LM contributed to reviewing and editing the manuscript. All authors read and approved the final manuscript.

\section{Funding}

Not applicable.

Availability of data and materials

Not applicable.

Ethics approval and consent to participate

Not applicable.

\section{Consent for publication}

The patient in the case report provided written consent for her pictures and case report to be used for research and publication purposes. A copy of the written consent is available for the editor's review upon request.

\section{Competing interests}

The authors declare that they have no competing interests.

\section{Author details}

${ }^{1}$ Department of Orthopedic Surgery, Naval Medical Center San Diego, 34800 Bob Wilson Dr, San Diego, CA, USA. ²Department of Anesthesia, Naval Medical Center San Diego, 34800 Bob Wilson Dr, San Diego, CA, USA.

Received: 31 December 2018 Accepted: 28 May 2019

Published online: 11 June 2019

\section{References}

1. Lee HC, Dewan N, Crosby L. Subcutaneous emphysema, pneumomediastinum, and potentially life-threatening tension pneumothorax. Pulmonary complications from arthroscopic shoulder decompression. Chest. 1992;101(5):1265-7.

2. Antonucci S, Orlandi P, Mattei PA, Amato F. Airway obstruction during arthroscopic shoulder surgery: anesthesia for the patient or for the surgeon? Minerva Anestesiol. 2006;72(12):995

3. Blumenthal S, Nadig M, Gerber C, Borgeat A. Severe airway obstruction during arthroscopic shoulder surgery. Anesthesiology. 2003;99(6):1455-6.

4. Borgeat A, Bird P, Ekatodramis G, Dumont C. Tracheal compression caused by periarticular fluid accumulation: a rare complication of shoulder surgery. J Shoulder Elb Surg. 2000;9(5):443-5.

5. Orebaugh SL. Life-threatening airway edema resulting from prolonged shoulder arthroscopy. Anesthesiology. 2003;99(6):1456-8.

6. Hynson JM, Tung A, Guevara JE, Katz JA, Glick JM, Shapiro WA. Complete airway obstruction during arthroscopic shoulder surgery. Anesth Analg. 1993;76(4):875-8.

7. Edwards DSF, Davis IM, Jones NAF, Simon DWF. Rapid tracheal deviation and airway compromise due to fluid extravasation during shoulder arthroscopy. J Shoulder Elb Surg. 2014;23(7):e163-5.

8. Venkat G, Moon YL, Na WC, So KY. Upper airway compromise by extravasated fluid: a rare complication after arthroscopic repair of atrophic cuff tear. Orthopedics. 2009;32(10):776-8.

9. Yoshimura E, Yano T, Ichinose K, Ushijima K. Airway obstruction involving a lanyngeal mask airway during arthroscopic shoulder surgery. J Anesth. 2005;19(4):325-7.

10. Ogilvie-Harris DJ, Boynton E. Arthroscopic acromioplasty: extravasation of fluid into the deltoid muscle. Arthroscopy. 1990;6(1):52-4. 
11. Matthews LS, Fadale PD. Subacromial anatomy for the arthroscopist. Arthroscopy. 1989;5(1):36-40

12. De Bast Y, De Backer D, Moraine JJ, Lemaire M, Vandenborght C, Vincent JL. The cuff leak test to predict failure of tracheal extubation for laryngeal edema. Intensive Care Med. 2002;28(9):1267-72.

13. Chung YH, Chao TY, Chiu CT, Lin MC. The cuff-leak test is a simple tool to verify severe laryngeal edema in patients undergoing long-term mechanical ventilation. Crit Care Med. 2006;34(2):409-14.

14. Rains DD, Rooke GA, Wahl CJ. Pathomechanisms and complications related to patient positioning and anesthesia during shoulder arthroscopy. Arthroscopy. 2011;27(4):532-41.

15. Morrison DS, Schaefer RK, Friedman RL. The relationship between subacromial space pressure, blood-pressure, and visual clarity during arthroscopic subacromial decompression. Arthroscopy-the Journal of Arthroscopic and Related Surgery. 1995;11(5):557-60

16. Memon M, Kay J, Gholami A, Simunovic N, Ayeni OR. Fluid extravasation in shoulder arthroscopic surgery a systematic review. Orthop I Sports Med. 2018;6(5).

17. Bergstrom R, Gillquist J. The use of an infusion pump in arthroscopy. Arthroscopy. 1986;2(1):41-5.

18. Mayo M, Wolsky R, Baldini T, Vezeridis PS, Bravman JT. Gravity fluid flow more accurately reflects joint fluid pressure compared with commercial peristaltic pump Systems in a Cadaveric Model. Arthroscopy. 2018;34(12):3132-8.

19. Smith CD, Shah MM. Fluid gain during routine shoulder arthroscopy. J Shoulder Elb Surg. 2008;17(3):415-7.

20. Khan F, Padmanabha S, Shantaram M, Aravind M. Airway compromise due to irrigation fluid extravasation following shoulder arthroscopy. J Anaesthesiol Clin Pharmacol. 2013;29(4):578-9.

21. Ichai C, Ciais JF, Roussel LJ, et al. Intravascular absorption of glycine irrigating solution during shoulder arthroscopy: a case report and follow-up study. Anesthesiology. 1996;85(6):1481-5.

\section{Publisher's Note}

Springer Nature remains neutral with regard to jurisdictional claims in published maps and institutional affiliations.

Ready to submit your research? Choose BMC and benefit from:

- fast, convenient online submission

- thorough peer review by experienced researchers in your field

- rapid publication on acceptance

- support for research data, including large and complex data types

- gold Open Access which fosters wider collaboration and increased citations

- maximum visibility for your research: over $100 \mathrm{M}$ website views per year

At $\mathrm{BMC}$, research is always in progress.

Learn more biomedcentral.com/submissions 